\title{
Pregnancy and Breastfeeding during Intrathecal Baclofen Therapy - A Case Study and Review
}

\author{
Takeshi Hara, ${ }_{1}^{1}$ Madoka Nakajima, ${ }_{1}^{1}$ Hidenori Sugano, ${ }_{1}$ Kostadin Karagiozov, ${ }^{1}$ Emiko Hirose, ${ }^{2}$ Keiko Goto, ${ }^{2}$ \\ and Hajime Arai ${ }^{1}$
}

We report the case of a young woman who received intrathecal baclofen therapy (ITB) and subsequently became pregnant and had a normal delivery. A 28-yearold woman with flexion myelopathy had anterior decompression with fusion at C4/5 and C5/6 levels. Clinical symptoms improved after surgery. However, when she was 29 years old, her symptoms steadily advanced to Modified Ashworth Scale 3 spasticity level in the lower legs, with pain in both of them and urinary retention tendency. Since a $25 \mu \mathrm{g}$ intrathecal baclofen injection improved her symptoms, an ITB pump system was implanted. After surgery, lower limb spasticity and urinary retention improved. Two years after ITB pump implantation, the patient married and became pregnant. The patient intended to have normal delivery but the induction of labor was ineffective and childbirth was completed by Cesarean section with lumbar anesthesia. The infant's Apgar score was 8 at $1 \mathrm{~min}$ and 9 at $5 \mathrm{~min}$, and birth-weight was 2,704 g. We measured the baclofen concentration in the patient's breast milk using high-performance liquid chromatography/tandem mass spectrometry. The level of baclofen in the breast milk was very low $(0.617 \mathrm{ng} / \mathrm{ml})$ and the predicted pharmacological effect on the infant was judged to be negligible. No withdrawal symptoms or muscle tone abnormalities were found after birth. Our findings indicate that ITB therapy could be considered for young women with severe spasticity, even if they plan to have children.

Keywords: intrathecal baclofen therapy, pregnancy

\section{Introduction}

Intrathecal baclofen (ITB) therapy has been used since 1992 to treat severe, intractable spasticity resulting from brain and spinal cord injury that is resistant to oral medication. LIORESAL ITB labeling' ${ }^{1)}$ indicates that 'For pregnant women, or women with the possibility of becoming pregnant, perform administration only when the benefits of treatment are judged to outweigh the risks' and 'For women who are breastfeeding,

\footnotetext{
${ }^{1}$ Department of Neurosurgery, Juntendo University, Tokyo, Japan ${ }^{2}$ Toray Research Center, Biomedical Analysis Research Div., No. 1 Biomedical Analysis Office, Tokyo, Japan
}

Received: October 25, 2017; Accepted: April 2, 2018

Online June 25, 2018

Copyright $₫ 2018$ by The Japan Neurosurgical Society This work is licensed under a Creative Commons AttributionNonCommercial-NoDerivatives International License. it is recorded that breastfeeding should be avoided while this drug is being administered.' This reflects the fact that oral baclofen has been shown to increase the incidence of omphaloceles (ventral hernias) in rat fetuses. This study used a dose equivalent up to 13 times the maximum oral dose recommended for human use on a $\mathrm{mg} / \mathrm{kg}$ basis, or 3 times this dose on a $\mathrm{mg} / \mathrm{m}^{2}$ basis; this dose also reduced food intake and weight-gain in the dams. This abnormality was not seen in mice or rabbits. However, there are no adequate and wellcontrolled studies of this in pregnant women. Baclofen should therefore only be used during pregnancy if the potential benefits outweigh the potential risk to the fetus. In nursing mothers treated with therapeutic doses of oral baclofen, the active substance passes into the breast milk. However, it is not known whether detectable levels of this drug are present in the breast milk of nursing mothers receiving ITB. As a general rule, nursing should only be undertaken by patients receiving ITB if the potential benefits outweigh the potential risk to the infant.

Animal tests have reported the transfer of baclofen across the placenta and into breast milk. ${ }^{2}$ However, the contraindication of ITB therapy for women who may become pregnant is based on the results of a single animal study and there are currently many aspects of the effects of baclofen on nursing infants that are unclear in the clinical setup.

The present report focuses on the case of a young woman who underwent ITB and subsequently became pregnant and had childbirth. We evaluated her condition over time and measured the baclofen concentration in her breast milk, investigating the safety of pregnancy, childbirth, and breastfeeding during ITB therapy.

\section{Case Report}

A 30-year-old woman was referred to us for the treatment of her spasticity. She had suffered a fall from a gymnastic apparatus during childhood and hit her head. The flexion myelopathy resulting from that had been progressing in stages for 12 years, and when she was 28 years old, she had anterior decompression with fusion surgery at C4/5 and C5/6 levels (Fig. 1). Clinical symptoms improved after surgery and she was able to return to her previous work. However, when she was 29 years old, her symptoms steadily advanced to Modified Ashworth Scale (MAS) 3 spasticity level in the lower legs, with pain in both of them and urinary retention tendency, so that an indwelling bladder catheter became necessary.

At the time of admission, neurological findings indicated hyperactive triceps, patellar and ankle reflexes on both sides, 

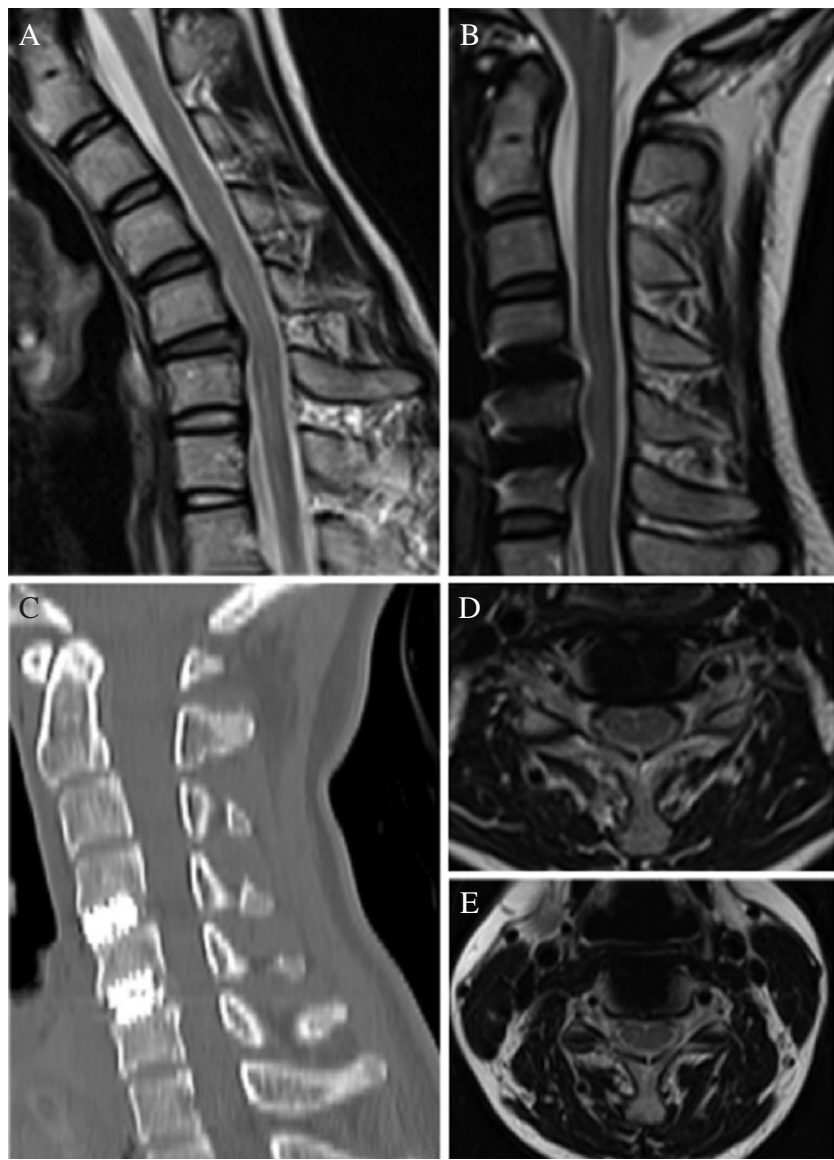

Fig. 1 Magnetic resonance imaging of the patient. Sagittal $\mathrm{T}_{2}$-weighted magnetic resonance images of (A) the pre-operative flexion position, showing compression of the ventral aspect of the spinal cord, and (B) after anterior cervical decompression and fusion. (C) Sagittal computed tomography imaging after anterior cervical decompression and fusion. Axial $\mathrm{T}_{2}$-weighted magnetic resonance images are shown after anterior cervical decompression and fusion at C4/5 (D) and at C5/6 (E).

and bilateral lower extremity weakness. Involuntary muscle contractions occurred often on the background of spasticity and the patient reported severe pain in both legs. We have used and reported the evaluation of the patient at the Department of Neurology at our hospital. The neurologist excluded the possibility of immunologic, demyelinating or hereditary spastic paraparesis.

To address the severe spasticity, a trial of ITB (Intrathecal Gabalon, Daiichi Sankyo, Tokyo) was performed. Since a $25 \mu \mathrm{g}$ intrathecal baclofen injection improved her lower limbs spasticity and pain, an ITB pump system was implanted. The catheter tip was positioned at the Th11 vertebra level. After surgery, lower limb spasticity improved to MAS 2, the indwelling bladder catheter was removed and the patient returned to work.

Two years after ITB pump implantation, the patient married and became pregnant. The pregnancy proceeded without problems, however, about one month before childbirth, lower limb spasticity deteriorated again to MAS 3 and lower limb pain recurred. The daily baclofen dose was therefore increased stepwise to $330 \mu \mathrm{g} /$ day (Fig. 2). The patient intended to have normal delivery but the induction of labor
12 weeks gentation Just before birth 28 days after delivery

\begin{tabular}{|c|c|c|c|}
\hline $\begin{array}{c}\text { Abdominal } \\
\text { circumference }\end{array}$ & $61 \mathrm{~cm}$ & $88 \mathrm{~cm}$ & $70 \mathrm{~cm}$ \\
\hline $\begin{array}{l}\text { Daily dose of } \\
\text { baclofen }\end{array}$ & $260 \mu \mathrm{g} / \mathrm{day}$ & $330 \mu \mathrm{g} / \mathrm{day}$ & $330 \mu \mathrm{g} / \mathrm{day}$ \\
\hline $\begin{array}{c}\text { Modified } \\
\text { Ashworth scale }\end{array}$ & 2 & 3 & 2 \\
\hline & S2y & & \\
\hline
\end{tabular}

Fig. 2 Photographs and parameters (abdominal circumference, daily dose of baclofen, and modified Ashworth scale) in perinatal period.

was ineffective and childbirth was completed by Cesarean section with lumbar anesthesia. The infant's Apgar score was 8 at $1 \mathrm{~min}$ and 9 at $5 \mathrm{~min}$, and birth-weight was $2,704 \mathrm{~g}$. Muscle tone and respiration were normal, indicating the absence of drug withdrawal symptoms following the intrauterine exposure to baclofen and even after 1 year, no developmental abnormalities have been observed. Since breastfeeding was contraindicated in the drug package documentation, it was not performed.

The lower limbs spasticity gradually improved after delivery and reached MAS 2 with a daily dosage of $330 \mu \mathrm{g}$ baclofen/day.

To evaluate the possibility of infant exposure to baclofen during breast-feeding, we measured the level of baclofen in the breast milk of this patient after childbirth with her informed consent. The daily ITB dosage was $330 \mu \mathrm{g} / \mathrm{day}$ when the sample was taken. In collaboration with the Toray Research Center, we pre-processed a breast milk sample using deproteinization and then analyzed it using high-performance liquid chromatography/tandem mass spectrometry. Adjustment was performed using a calibration curve and a blank serum sample (normal control) with a Q sample for accuracy control. The parameters of accuracy in this method are as follows: correlation coefficient 0.9984 , Regression equation $y=0.0342 x+0.000268$, Accuracy 99.5-102.5 (\%).

We also validated the method using a serum blank after being adjusted with synthetic milk (formula powdered milk; Hagukumi/Morinaga Milk Industry, Tokyo) (Original unpublished method of Toray Industries Research Center).

As a result of these tests, the baclofen concentration detected in breast milk was $0.617 \mathrm{ng} / \mathrm{ml}$.

\section{Discussion}

Currently using ITB for pregnant woman is limited, but there are some reports that ITB was employed to treat spasticity in few such cases. Table 1 shows 11 published cases of pregnancy and childbirth during ITB therapy. ${ }^{3-10)}$ The literature reported no adverse effect in the development of infants born to patients with ITB therapy. In addition, in these 
Table 1 All reports of intrathecal baclofen use during pregnancy

\begin{tabular}{|c|c|c|c|c|c|c|c|}
\hline \multirow[b]{2}{*}{ Case } & \multirow[b]{2}{*}{ Reference } & \multirow[b]{2}{*}{ Age } & \multirow[b]{2}{*}{ Delivery } & \multicolumn{3}{|c|}{ Dose of baclofen ( $\mu \mathrm{g} /$ day) } & \multirow[b]{2}{*}{ Pathology } \\
\hline & & & & $\begin{array}{c}\text { During } \\
\text { pregnancy }\end{array}$ & $\begin{array}{c}\text { Just before } \\
\text { delivery }\end{array}$ & $\begin{array}{c}\text { After } \\
\text { delivery }\end{array}$ & \\
\hline 1 & Roberts et al. $^{10)}$ & 23 & Cesarean section & 150 & 375 & & Spinal cord injury T7 \\
\hline 2 & Delhaas et al. ${ }^{4)}$ & 29 & Cesarean section & 1200 & 1400 & & Spinal cord injury C5/6 \\
\hline 3 & Blanco-Canto et al. ${ }^{3)}$ & 30 & Vacuum-assisted vaginal delivery & 200 & 200 & & Generalized dystonia \\
\hline $4 a$ & Muñoz et al. ${ }^{8)}$ & 37 & Cesarean section & 140 & 140 & & Spinal cord injury C5 \\
\hline $4 b$ & Muñoz et al. ${ }^{8)}$ & 38 & Cesarean section & Unknown & & & Spinal cord injury C5 \\
\hline 5 & Morton et al. $\left.{ }^{7}\right)$ & 27 & Vaginal delivery & 200 & 200 & & Spinal cord injury T9 \\
\hline $6 a$ & Morton et al. ${ }^{7)}$ & 21 & Vaginal delivery & 200 & 200 & 220 & Athtoid dystonic cerebral palsy \\
\hline $6 b$ & Morton et al. ${ }^{7)}$ & 23 & Vaginal delivery & 400 & 430 & 465 & Athtoid dystonic cerebral palsy \\
\hline 7 & Morton et al. ${ }^{7)}$ & 35 & Cesarean section & 785 & 795 & & Spastic athethoid cerebral palsy \\
\hline 8 & deVries-Rizzo et al. ${ }^{5)}$ & 18 & Vaginal delivery & 440 & 440 & & Myelitis \\
\hline 9 & Ali Sakra Esa et al. ${ }^{6}$ & 28 & Vaginal delivery & Unknown & & & Cerebral palsy \\
\hline This case & & 30 & Cesarean section & 300 & 330 & 330 & Cervical spondylotic myelopathy \\
\hline
\end{tabular}

reports, there were no description on feeding methods and baclofen concentration in milk. This case report is the first report demonstrating baclofen concentration in breast milk.

Unfortunately, in this case we could not measure serum baclofen concentration of the infant immediately after birth. Also, since the infant did not take breast milk, its effect could not be sufficiently verified. A previous study reported that human milk produced over $26 \mathrm{~h}(395 \mathrm{ml})$ during oral administration of baclofen contained a total of $22 \mu \mathrm{g}$ baclofen, which corresponded to about $0.01 \%$ of the dose. ${ }^{11}$ Assuming the average expected daily milk production and the baclofen concentration of $0.617 \mathrm{ng} / \mathrm{ml}$ determined in the present study, the total baclofen secreted was estimated at around $0.24 \mu \mathrm{g}$. This is an extremely small amount, as compared with the initially recommended infant dose of $0.312 \mathrm{mg} / \mathrm{kg}$ bodyweight (assuming the average bodyweight of 4-year-old infant as $16 \mathrm{~kg}$ ).

This indicated that the level of baclofen found in the milk during intrathecal administration was much lower than that observed during oral administration. The amount of baclofen delivered by breast milk produced by a mother during ITB therapy is thus only around $0.02 \%$ of this clinical dose. This demonstrates a very low exposure of the infant to baclofen in breast milk, and the pharmacological effect can be expected to be negligible.

On the other hand, there are three main advantages of breastfeeding, these include nutritional advantages, immunological advantages, and promotion of the mother-child interaction. ${ }^{12-14)}$ Regarding the first one of these, and to some extent the second, recent advances in nutrition science and improvements in synthetic milk have ensured that synthetic milk nursing is not inferior to breastfeeding. However, breastfeeding is still promoted because it is an act of love between mother and child that helps to build a trusting relationship, boosts the mother's self-awareness, and promotes the infant's mental and emotional development; these outcomes may not be achieved as effectively using synthetic milk. ${ }^{13,14)}$ To date, strong restrictions have been placed on breastfeeding by women who are undergoing ITB therapy. The results of this report found little transfer of baclofen to breast milk and we thus predict that the effects on nursing infants are likely to be negligible. These findings suggest that women may be able to breastfeed while undergoing ITB therapy and this option has to be considered in the future.

While many points remain to be clarified with respect to the optimal childbirth method and daily ITB dosage during pregnancy, we consider that the case described in this report shows that even women who may become pregnant can receive the benefits of this therapy. At the present time, the introduction of ITB therapy for women of childbearing age requires the approval of their physician, and it is usually not recommended.

The LIORESAL ITB product labeling") states "In mothers treated with oral LIORESAL (baclofen USP) in therapeutic doses, the active substance passes into the breast milk. It is not known whether detectable levels of drug are present in breast milk of nursing mothers receiving LIORESAL INTRATHECAL. As a general rule, nursing should be undertaken while a patient is receiving LIORESAL INTRATHECAL only if potential benefit justifies the potential risk to the infant." However, since some previous cases have reported symptoms of baclofen withdrawal in infants of mothers who received oral baclofen, including convulsive seizures, ${ }^{9)}$ ITB therapy may actually provide a safer alternative in these patients.

\section{Conclusion}

The young female patient described in the present study received ITB therapy prior to and during pregnancy and childbirth without any apparent adverse effects on the patient or her infant. These findings, together with those reported previously, indicate that baclofen administration is possible during pregnancy and childbirth. Furthermore, we found that the baclofen concentration in the patient's breast milk was extremely low. Excessive restriction of access to ITB therapy could disadvantage female patients throughout their childbearing years. Our preliminary findings warrant further larger-scale clinical investigations to obtain a robust evidence base that could lead to future access to ITB therapy. 


\section{Acknowledgment}

We thank the Toray Research Center, Biomedical Analysis Research Div., No. 1 Biomedical Analysis Office for conducting the analysis of baclofen in breast milk.

\section{Conflicts of Interest Disclosure}

All authors have no conflict of interest.

\section{References}

1) LIORESAL ITB labeling http://www.accessdata.fda.gov/drugsatfda docs/label/2011/020075s021lbl.pdf.

2) Yamamoto H, Kuki M, Ozaki M: Absorption, distribution, metabolism, and excretion of $\beta$-( $p$-chlorophenyl)-GABA (baclofen) (report no. 3) placental passage and transfer to mother's milk. Appl Pharmacol 14: 115-120, 1977

3) Blanco-Cantó ME, Porta-Etessam J, Santos-Bueso E, González N: Fluctuating diplopia as an initial manifestation of polycythemia vera. Neurologia 31: 130-131, 2016

4) Delhaas EM, Verhagen J: Pregnancy in a quadriplegic patient treated with continuous intrathecal baclofen infusion to manage her severe spasticity. Case report. Paraplegia 30: 527-528, 1992
5) DeVries-Rizzo M, Warren D, Delaney G, Levin S, Campbell C, DeRibaupierre S: Intrathecal baclofen and pregnancy: implications for clinical care. Can J Neurosci Nurs 31: 21-24, 2009

6) Ali Sakr Esa W, Toma I, Tetzlaff JE, Barsoum S: Epidural analgesia in labor for a woman with an intrathecal baclofen pump. Int J Obstet Anesth 18: 64-66, 2009

7) Morton CM, Rosenow J, Wong C, Kirschner KL: Intrathecal baclofen administration during pregnancy: a case series and focused clinical review. $P M R$ 1: 1025-1029, 2009

8) Muñoz FC, Marco DG, Pérez AV, Camacho MM: Pregnancy outcome in a woman exposed to continuous intrathecal baclofen infusion. Ann Pharmacother 34: 956, 2000

9) Ratnayaka BD, Dhaliwal H, Watkin S: Drug points: Neonatal convulsions after withdrawal of baclofen. BMJ 323: 85, 2001

10) Roberts AG, Graves CR, Konrad PE, et al.: Intrathecal baclofen pump implantation during pregnancy. Neurology 61: 1156-1157, 2003

11) Eriksson G, Swahn CG: Concentrations of baclofen in serum and breast milk from a lactating woman. Scand J Clin Lab Invest 41: 185-187, 1981

12) Section on Breast feeding. Breastfeeding and the use of human milk. Pediatrics 129: 827-841, 2012

13) American Academy of Pediatrics: Breastfeeding and the use of human milk. Pediatrics 100: 1035-1039, 1997

14) Uemura K, Aono T: Significance of breastfeeding (special issue, postpartum). Obstet Gynecol Treatment 82: 19-21, 2001

Corresponding author:

Takeshi Hara, Department of Neurosurgery, Juntendo University, 2-1-1 Hongo, Bunkyo-ku, Tokyo 113-8421, Japan.

$\bowtie$ thara79nouge@gmail.com 